\title{
High Dose Methotrexate and Leucovorin Rescue Therapy in Childhood Malignancies: Experience in Resource-Limited Country
}

\author{
SHORMIN ARA FERDOUSI ${ }^{1}$, AFROZA AKHTER ${ }^{2}$, KAMRUN NAHAR $^{3}$, AFIQUL ISLAM $^{4}$
}

\begin{abstract}
Background: Administration of high dose methotrexate (HDMTX) needs meticulous monitoring. Limitations in the availability of trained staff and adequate infrastructure often are great problems in the developing country like Bangladesh.

Objective: The aim of this study was to evaluate the HDMTX toxicities by monitoring biochemical and serological markers where facility for serum MTX level in a tertiary care centre (Combined Military Hospital, Dhaka) of Bangladesh is available.

Methods: An explorative study was done among twelve cases with a confirmed diagnosis of Pre-B \& T cell ALL, Burkitt's lymphoma, $T$ cell lymphoma and osteosarcoma. All of them received four cycles of HDMTX as part of their treatment. Demographic profile, details of HDMTX infusion and Leucovorin rescue and toxicities were collected and analyzed.
\end{abstract}

Results: We evaluated and compared toxicity of repeated courses of high dose methotrexate (HDMTX) in five groups of pediatric patients. Neutropenia was observed in $83.3 \%$ case and vomiting in $70 \%$ during chemotherapy. Diarrhoea $12.5 \%$, oral mucositis in $56.20 \%$ patients were noted. Low hemoglobin level, was observed in $14.58 \%$, thrombocytopenia in $20.80 \%$ patients. Vomiting and diarrhea was most frequent in cycle $2>1>3>4$, whereas mucositis, fever was most frequent in Cycle $1>2>3>4$ and raised serum transaminase in cycle $3>2>1>4$. Two patients had $<100$ creatinine clearance. There was significant relationship between neutropenia with toxicities like vomiting and mucositis $(p<0.05)$.

Conclusion: The administration of HDMTX therapy was found to be safe without any life threatening adverse effect in a developing country like Bangladesh where there is lacking of lab support and adequate supportive management.

Keywords: Acute Lymphoblastic Leukemia; children, HDMTX, Leucovorin, Rescue therapy.

\section{Introduction}

Fortunately cancer in children and adolescents is rare, but it has been noticed that the overall incidence of childhood cancer has been slowly increasing since $1975 .{ }^{1}$ Over the last two decades dramatic

1. Colonel, Classified Child Specialist \& Pediatric Oncologist, Department of Pediatrics, Combined Military Hospital, Dhaka, Bangladesh.

2. Major, Classified Child Specialist, Department of Pediatrics, Combined Military Hospital, Dhaka, Bangladesh.

3. Major, Classified Specialist in Medical Oncology (Pediatrics), Combined Military Hospital, Dhaka, Bangladesh.

4. Professor, Dept. of Pediatric Hematology and Oncology, Bangabandhu Sheikh Mujib Medical University, Dhaka, Bangladesh.

Correspondence: Dr. Shormin Ara Ferdousi, Col, Child Specialist and Pediatric Oncologist, Combined Military Hospital, Dhaka, Bangladesh. E-mail: shormin@gmail.com improvements have been achieved in pediatric malignancies, ${ }^{1}$ survival rate has been raised to 80 $90 \%$ depending on advancement of disease. Many of the improvements are due to use of treatment with multidispilnary approach. ${ }^{2}$

Methotrexate (MTx) first demonstrated efficacy as a chemotherapeutic agent in acute lymphoblastic leukemia (ALL) in $1947 .{ }^{3}$ Since that time, it became one of the most widely studied anticancer agents. Methotrexate is unique; in that it can be administered safely in a multitude of dosing strategies, including high-dose methotrexate (HD-MTX) which is defined as doses $\geq 1 \mathrm{~g} / \mathrm{m} 2 .{ }^{4}$ It is a classical antifolate that inhibits dihydrofolic acid reductase and thymidylate synthase, enzymes that are crucial components of 
purine nucleotide and thymidylate synthesis pathways, and their inhibition ultimately interferes with DNA synthesis, repair, and cellular replication. ${ }^{5,6}$ It is historically and currently indicated for use in pediatric neoplastic disorders, such as ALL, meningeal leukemia, osteosarcoma, some brain tumors, and nonHodgkin's lymphoma. ${ }^{7-9}$ These neoplastic indications are well established and researched, almost always required combination therapy. ${ }^{10}$

In the late 1960s, Djerassi et al. showed that increasing the dosage of MTX would secure new remissions in patients who had relapsed while receiving the drug at a lower dosage. Wang et al. demonstrated that an intravenous (IV) MTX infusion at $500 \mathrm{mg} / \mathrm{m}^{2}$ over 24 hours would produce sufficiently high levels of the drug in cerebrospinal fluid to eradicate central nervous system (CNS) leukemia. ${ }^{11}$ High-dose Methotrexate (HDMTX, i.e., higher than $1 \mathrm{~g} \mathrm{D} \mathrm{m}^{2}$ ), is a common component of many chemotherapeutic protocols for children with ALL. ${ }^{12}$ The combination of intrathecal chemotherapy with systemic high-dose MTX and Leucovorin rescue is an effective CNSdirected therapy. Cranial irradiation plays a crucial part in acute leukemia treatment but can also result in adverse effects on the developing brain. The elimination of cranial irradiation from current treatment protocols has improved the neurocognitive outcome without compromising survival rates. ${ }^{13}$ The regular MTX dose of later years has been in the range of 5-8 $\mathrm{g} / \mathrm{m}^{2}$. The intravenous MTX dose has actually varied from 2 to $33.6 \mathrm{~g} / \mathrm{m}^{2}$. The highest dose, $33.6 \mathrm{~g} / \mathrm{m}^{2}$, has been without intrathecal instillation. ${ }^{14}$ In various disease doses of MTX varies, for pediatric osteosarcoma doses of $12 \mathrm{gm} / \mathrm{m} 2 /$ of MTX followed by leucovorin ${ }^{15,16}$ then surgery follows with doxorubicin and cisplatin. ALL has dose ranges from 1-8 $\mathrm{g}$ per $\mathrm{m}^{2} .{ }^{17}$ The dose depends on the combination and whether it is CNS involved at diagnosis. ${ }^{17}$ Meningeal leukemia, doses of intrathecal MTX are $2 \mathrm{~g} / \mathrm{m}^{2} /$ week, followed by systemic infusion of MTX within the range of $1-5 \mathrm{~g} / \mathrm{m} 2$ with leucovorin rescue. ${ }^{18}$ The recommended doses for intrathecal MTX are $6 \mathrm{mg}$ for a child under 1 year of age, $8 \mathrm{mg}$ for a 1 year old, 10 $\mathrm{mg}$ for a 2 year old, and $12 \mathrm{mg}$ for any child over the age of $3 .^{19}$

Post-HDMTX toxicity is common, and associated with increased risk of infections and interruption of maintenance treatment, which has been linked to a reduced cure rate. The enzyme methylene tetrahydrofolatereductase (MTHFR) catalyses the irreversible conversion of 5,10-methylene tetrahydrofolate to 5-methyl tetrahydrofolate. ${ }^{20}$ The side effects profile of MTX varies markedly according to dose and duration.

The HD MTX usually deliver in lethal dose over 4 to 36 hours infusion and require 2-3 days period of multiple leucovorin doses to terminate the toxic effects of MTX which termed as Rescue. Successful rescue by leucovorin depends on rapid elimination of MTX by kidneys, which requires aggressive pretreatment as well as post treatment hydration and urinary alkalization. ${ }^{10}$ Low dose $\left(<30 \mathrm{mg} / \mathrm{m}^{2}\right)$ and intermediate dose $\left(<1 \mathrm{gm} / \mathrm{m}^{2}\right)$ MTX usually not provide therapeutic concentration in CSF. ${ }^{10}$ Known side effect and toxic manifestations include bone marrow depression, mucositis, diarrhea, liver and kidney dysfunction, dermatitis, and neurologic disturbances. However, severe and fatal reactions have also been reported following this method of administration. ${ }^{21}$ Alkalinization, vigorous hydration and rescue with leucovorin are needed to minimize the toxicity of this drug. 22

There is great concern about the quality of life among the directed therapy is an integral part of the treatment of pediatric malignancies especially ALL. ${ }^{23}$ Despite more than 50 years of evaluation and treatment refinements, important questions remain to be addressed about how best to use methotrexate for children with ALL.

The aim of this study was to evaluate the HDMTX toxicities by monitoring biochemical and serological markers where facility for serum MTX level is not available.

\section{Materials and Methods}

This explorative study was conducted in the paediatric haematology and oncology unit of Department of Paediatric in Combined Military hospital $(\mathrm{CMH})$, Dhaka, Bangladesh. Twelve (12) childhood cancer patients with ages ranged from 2 to 16 years who received high dose Methotrexate from July 2014 to December 2015 in the same institute were selected for this study. They were newly diagnosed confirmed cases of childhood cancer like ALL (T Cell \& Pre B Cell High risk group), NHL (T cell, Burkitt lymphoma stage IV), osteosarcoma were treated with disease specific intensive treatment protocol. Exclusion criteria were 1. Patients who received low or intermediate 
doses of MTx, 2. Patients with Standard risk of malignant disease. 3. Patient with impaired renal function 4. Cytogenetics was excluded to categorize high risk.

For each child a semi-structured questionnaire was prepared. Informed written consents were obtained from parents of patients. For every child proper counseling had been done with their parents providing adequate information about diet, living habits, oral and anal care and most importantly maintaining hygiene with hand washing method.

The confirmation of diagnosis of ALL was done by cytomorphological and immunophenotyping of Peripheral blood and Bone marrow smears, risk stratification was done by cytogenetics. In case of NHL \& Osteosarcoma diagnosis was done by histopathology (by FNAC, excision tissue biopsy) of lymph node or palpable tumor mass and immunohistochemistry. Opinion were taken from surgeon, pathologists. Assessment of the staging of the disease was made on physical examination, radiology and laboratory studies. Intensified systemic combination chemotherapy was administered to all patients, for T Cell ALL variety TMC T Cell, Pre B ALL Cell variety TMC Pre B protocol, lymphoblastic lymphoma (LL) BFM protocol, for Osteosarcoma EUROMOS chemotherapy protocol were provided. During proving High Dose Methotrexate, dose and schedule were chosen according to the disease specific protocol. In case of Pre B ALL $3 \mathrm{gm} / \mathrm{m}^{2}$, Tcell ALL $5 \mathrm{gm} / \mathrm{m}^{2}$, NHL-T cell $5 \mathrm{gm} / \mathrm{m}^{2}$, NHL-Burkitt 8 $\mathrm{gm} / \mathrm{m} 2$, Osteosarcoma $12 \mathrm{gm} / \mathrm{m}^{2}$. First dose of leucovorin rescue was given at 42 hours from the start of HD-MTX infusion in ALL ( $T$ cell, Pre B High risk) \& $\mathrm{NHL}-\mathrm{T}$ cell and 24 hours in case of osteosarcoma and NHL (Burkitt) at dose of $15 \mathrm{mg} / \mathrm{m}^{2} 6$ hourly $10-12$ doses. All patients received appropriate supportive care with Antimicrobials, blood and platelet transfusions and nutritional diet.

The following clinical data were collected: details of HDMTX infusion, urine $\mathrm{pH}$, fluid intake, and urine output. Details of leucovorin rescue including starting time, doses \& duration of rescue was recorded. Toxicities were observed and recorded like Nausea, vomiting, diarrhea, mucositis, myelosuppression, fever. Effects like hematological parameter, liver function, kidney function were recorded .Additional hospitalization delay for the next cycle of chemotherapy was not assessed in this study. Stage and measurement of toxicities severity were done by World Health Organization's (WHO's) "Toxicity Grading Scale for Determining the Severity of Adverse Events."

Hematological Toxicity Grade-1: Hemoglobin 10-10.9 $\mathrm{gm} / \mathrm{dL}$, Absolute Neutrophil Count (ANC) 750-1200/ $\mathrm{mm}^{3}$, Platelets $75,000-99,999 / \mathrm{mm}^{3}$, Grade-2: Hemoglobin 7.0-9.9 gm/dL, ANC $400-749 / \mathrm{mm}^{3}$, Platelets 50,000-75,000/mm ${ }^{3}$, Grade-3: Hemoglobin $<7 \mathrm{gm} / \mathrm{dL}$, ANC 250-399/ $\mathrm{mm}^{3}$ Platelets 25,00049,999/ $\mathrm{mm}^{3}$, Grade-4: Hemoglobin- cardiac failure secondary to anemia, ANC $<500 / \mathrm{mm}^{3}$, Platelets $<25,000 / \mathrm{mm}^{3}$.

Hepatotoxicity by ALT (SGPT) Grade-1 is 1.1 4.9xULN Grade-2 is $5-9.9 x U L N$, Grade-3 is $10-$ $15 x U L N$, Grade is $>15 x U L N$.

Gastrointestinal toxicity like Nausea Grade-1: mild or transient, Grade-2: Moderate-decreased oral intake, Grade-3: Severe-little oral intake, Grade-4 Unable to ingest food or fluid for more than 24 hours. Vomiting grade-1 is 1 episode/day, grade-2 is 2-3 episodes/ day, grade- 3 is 4-6 episodes/day, grade- 4 is greater than 6 episodes per day or intractable vomiting. For diarrhea grade-1: slight change in consistency and/or frequency of stools, grade-2: liquid stools, grade-3: liquid stools greater that $4 \mathrm{x}$ the amount or number normal for this child grade 4 Liquid stools greater than $8 \mathrm{x}$ the amount or number normal for this child. Stomatitis grade 1: Mild discomfort, grade-2: Painful, difficulty swallowing, but able to eat and drink. Grade3: Painful: unable to swallow solids, grade 4 Painful: unable to swallow liquids; requires IV fluids.

Nephrotoxicity were graded by creatinine measurement according to age group. For children of 2 to 12 years of age grade $1: 0.7-1.0 \mathrm{mg} / \mathrm{dL}$, grade2: $1.1-1.6 \mathrm{mg} / \mathrm{dL}$, grade $3: 1.7-2.0 \mathrm{mg} / \mathrm{dL}$, grade 4 : $>2.0 \mathrm{mg} / \mathrm{dL}$. For children greater than 12 Years of age grade-1: $1.0-1.7 \mathrm{mg} / \mathrm{dL}$, grade-2: $1.8-2.4 \mathrm{mg} / \mathrm{dL}$, grade-3: $2.5-3.5 \mathrm{mg} / \mathrm{dL}$, grade-4: $>3.5 \mathrm{mg} / \mathrm{dL}$.

All this information had enrolled to a questionnaire. Data analysis was done by using statistical package for social science (SPSS 20). The findings were considered statistically significant at $P$ value of $<0.05$.

There had not been any ethical compromise in preparation of this report nor there any possibility of any harm for anybody from the dissemination of this report. This study did not give any extra financial burden to the family. Reassurance was given to parents 
regarding safety during study and benefit for clinicians for future patients.

\section{Results}

We observed total twelve patients were in this study. Among them nine were male and three were female child. Body Surface Area (BSA) ranges from $0.62 \mathrm{~m}^{2}-1.2$ $\mathrm{m}^{2}$, average $0.8 \mathrm{~m}^{2}$. Age ranges from 23 months to 12 years. Patient's characteristics were shown in Table I.

Table I

Patient's characteristics ( $n=12)$

\begin{tabular}{|c|c|c|c|}
\hline \multirow{2}{*}{$\begin{array}{l}\text { Characteristics } \\
\text { Gender }\end{array}$} & \multirow{2}{*}{$\begin{array}{l}\text { Variables } \\
\text { Male }\end{array}$} & \multicolumn{2}{|c|}{ Number Percentage } \\
\hline & & 9 & 75.0 \\
\hline & Female & 3 & 25.0 \\
\hline \multirow[t]{2}{*}{ Age at diagnosis } & $1-10$ years & 8 & 66.7 \\
\hline & $>10$ years & 4 & 33.3 \\
\hline \multirow{6}{*}{ Diseases } & ALL- 09 & 9 & 75.0 \\
\hline & Pre B All & All 7 & 58.3 \\
\hline & $\mathrm{T}$ cell All & II 2 & 16.7 \\
\hline & NHL Burkitt's & 1 & 8.3 \\
\hline & NHL T-Cell & 1 & 8.3 \\
\hline & Osteosarcoma & 1 & 8.3 \\
\hline $\begin{array}{ll}\text { BSA Range } & \begin{array}{l}\text { Redian } \\
\text { Median }\end{array}\end{array}$ & \multicolumn{3}{|c|}{$\begin{array}{c}0.62-1.2 \\
0.91\end{array}$} \\
\hline
\end{tabular}

We evaluated and compared toxicity of high dose methotrexate (HDMTX) repeated courses in five groups of pediatric patients seven patients had Pre-B ALL and were treated with four courses of HD-MTX (total of 28 courses); two patients had ALL- T cell and were treated with four courses of HD-MTX (total 08 courses), one patient with $\mathrm{NHL}$ T-cell received 04 cycles of HDMTX, one patient of NHL (Burkitt) treated with four courses of HD-MTX, one patient diagnosed as nonmetastatic osteosarcoma of extremities, treated with four courses of HD-MTX in his preoperative phase of treatment. All the cycles met the prerequisite criteria of prehydration, urine alkalanization. During methotrexate infusion duration of methotrexate infusion, rate of flow, duration of post hydration along with appropriate leucovorin rescue also considered strictly.

The frequencies of various toxicities observed with HDMTX are shown in Table II.

Hematological toxicity (83.3\%) and vomiting (70\%) were the most frequent toxicity

Among all GIT Toxicity, vomiting (70\%) was the most frequent; but only $14.6 \%$ cycles had grade 3 [6-10 episodes of vomiting]. Diarrhea occurred in $12.5 \%$ cases, however grade 3 [7 to 9 episodes of diarrhea] and 4 [more than 9 episodes of diarrhea] were not observed in any of the cycles. Oral mucositis occurred

Table II

Observed Toxicities with HD-MTX infusion by cycle number

\begin{tabular}{lccccc}
\hline Toxicities & $\begin{array}{c}\text { Cycle -1 } \\
\text { No (\%) }\end{array}$ & $\begin{array}{c}\text { Cycle-2 } \\
\text { No (\%) }\end{array}$ & $\begin{array}{c}\text { Cycle -3 } \\
\text { No (\%) }\end{array}$ & $\begin{array}{c}\text { Cycle -4 } \\
\text { No }(\%)\end{array}$ & $\begin{array}{c}\text { Cycle -5 } \\
\text { No } \%)\end{array}$ \\
\hline Vomiting & & & & & \\
$\quad$ Total & $09(75)$ & $10(83.3)$ & $08(66.7)$ & $07(58.3)$ & $34(70.9)$ \\
$\quad$ Grade 1 \& & $06(50)$ & $07(58.3)$ & $07(58.3)$ & $07(58.3)$ & $27(56.3)$ \\
$\quad$ Grade 3 \& & $03(25)$ & $03(25)$ & $01(08.3)$ & $0(0)$ & $07(14.6)$ \\
Diarrhea & & & & & \\
$\quad$ Total & $02(16.7)$ & $03(25)$ & $01(1.3)$ & $0(0)$ & $06(12.5)$ \\
$\quad$ Grade 1 \& & $02(16.2)$ & $03(25)$ & $01(1.3)$ & $0(0)$ & $06(12.5)$ \\
$\quad$ Grade 3\& & $0(0)$ & $0(0)$ & $0(0)$ & $0(0)$ & $0(0)$ \\
Mucositis & & & & & \\
$\quad$ Total & $09(75.0)$ & $08(66.7)$ & $07(58.3)$ & $03(25)$ & $27(56.2)$ \\
$\quad$ Grade 1 \& & $07(58.3)$ & $06(50.0)$ & $07(58.3)$ & $03(25)$ & $23(47.9)$ \\
$\quad$ Grade 3 \& 4 & $02(16.7)$ & $02(16.7)$ & $0(0)$ & $0(0)$ & $04(8.3)$ \\
Fever & $05(41.7)$ & $04(33.3)$ & $03(25)$ & $02(16.7)$ & $14(29.2)$ \\
Raised ALT & $02(16.7)$ & $01(8.3)$ & $03(25)$ & $0(0)$ & $06(12.5)$ \\
Creatinine clearance $(<100)$ & $01(8.3)$ & $0(0)$ & $0(0)$ & $01(8.3)$ & $02(4.12)$ \\
Impaired GFR & $01(8.3)$ & $0(0)$ & $0(0)$ & $01(8.3)$ & $02(4.12)$ \\
Neutropenia & $12(100)$ & $10(83.3)$ & $10(83.3)$ & $08(66.7)$ & $40(83.3)$ \\
Thrombocytopenia & $05(41.7)$ & $03(25)$ & $01(8.3)$ & $01(8.3)$ & $10(20.8)$ \\
\hline
\end{tabular}


in $56.2 \%$ patients and grade 3 , as defined by presence of painful ulcer erythema/edema and cannot tolerate diet $\&$ can swallow liquid, occurred in $08.3 \%$. None needed parenteral nutrition.

Hematological toxicity in the form neutropenia (ANC $<1 \times 10^{9} / \mathrm{L}$ ) was observed in $83.30 \%$ patients. This changes starts to occur from day 5 of starting HDMTX cycle onwards and hematological recovery usually occurred by day 12 as evident by median ANC. These patients were managed by G-CSF except ALL patients for whom we waited for spontaneous recovery. Thrombocytopenia (platelet count $<50 \times 10^{9} / \mathrm{L}$ ) was observed in $20.8 \%$ patients (Table II). They were managed by transfusion of platelet concentrate.

Transient elevation of serum alanine transaminases (ALT) levels occurred in $12.5 \%$ cases, ranging from 5 to 30 times upper than normal limit. It was occurred in patient with Pre-B ALL \& osteosarcoma. They returned to normal level in subsequent follow-up. Nephrotoxicity (raised serum urea, creatinine, potassium and low GFR) was not observed but creatinine clearance $(\mathrm{CCr})<100$ found in two patients. Neurotoxicity (convulsion) did not occur in any patient.

Fever was observed in $29.2 \%$ cases, mostly seen in patients with Pre BALL, T cell ALL and Osteosarcoma.

Vomiting and diarrhoea was most frequent in cycle $2>1>3>4$, whereas mucositis, fever was most frequent in Cycle $1>2>3>4$ and raised serum transaminase (ALT) in cycle $3>2>1>4$.

There was significant relationship between neutropenia with toxicities like vomiting and mucositis were found $(p<0.05)$ (Table III) whereas others had no significant association.

Table-III

Toxicities in relation with neutropenia

\begin{tabular}{lccc}
\hline $\begin{array}{l}\text { Neutropenia vs. } \\
\text { other toxicities }\end{array}$ & $\begin{array}{c}\text { Neutropenia } \\
\text { present }\end{array}$ & $\begin{array}{c}\text { Neutropenia } \\
\text { absent }\end{array}$ & $\begin{array}{c}\text { P- } \\
\text { value }^{*}\end{array}$ \\
\hline No. of cycles=48 & $40 / 48(83.30)$ & $8 / 48(16.7)$ & \\
Vomiting & $30(75)$ & $02(25)$ & 0.002 \\
Diarrhea & $06(15)$ & $08(100)$ & 0.313 \\
Mucositis & $23(57.5)$ & $07(87.5)$ & 0.049 \\
Fever & $12(30)$ & $08(100)$ & 0.572 \\
Raised ALT & $05(12.5)$ & $07(87.5)$ & 0.687 \\
Thrombocytopenia & $09(22.5)$ & $07(87.5)$ & 0.464 \\
\hline
\end{tabular}

\section{Discussion}

Leukemia is a clonal disease resulting from genetic mutations and transformation of a single early progenitor myeloid or lymphoid cell. Despite much research the causes of acute leukemia remain largely unknown. ${ }^{24}$ It is the most common childhood malignancies, comprises $25-30 \%$ of all childhood cancers. Acute leukemias constitute $97 \%$ and Chronic myeloid leukemias constitute $3 \%$ of all childhood leukemias. peak incidence is between 2 and 5 years of age. ${ }^{25}$

$\mathrm{NHL}$, third most common childhood malignancy after leukemia and CNS tumor; represents approximately $6-8 \%$ of all malignancies in patients under 20 years of age. Median age of presentation is 10 years. Pediatric $\mathrm{NHL}$ is mostly (more than 95\%) high-grade and includes the following four major subtypes: (1) B- and T-lymphoblastic lymphoma (LL) (2) Burkitt lymphoma (BL) (3) Diffuse large B-cell lymphoma (DLBCL) (4) ALCL. ${ }^{25}$ At present, $80-90 \%$ of children with $\mathrm{NHL}$ are cured with intensive risk-adapted chemotherapy in the developed countries. ${ }^{26}$

Malignant bone tumors constitute approximately $6 \%$ of all childhood malignancies, osteosarcoma (54\%) is the most common among them in children under 20 years of age. ${ }^{25}$ Osteosarcoma (OS) is a pleomorphic malignant tumor of bone in which the proliferating spindle cells produce osteoid or immature bone. ${ }^{27}$ Advances in adjuvant and neo-adjuvant chemotherapy have improved the 5 year disease-free survival to more than $60 \%{ }^{28}$

Methotrexate is one of the folate antagonists used in different childhood malignancies like ALL and has been a mainstay of treatment ever since. A biological explanation for its efficacy may lie in the ability of lymphoblasts, particularly those of common ALL, to accumulate methotrexate, and the correlation of this ability with a better chance of long term survival. ${ }^{29}$ MTX exerts its cytotoxic effects by competitively inhibiting dihydrofolate reductase (DHFR), the enzyme responsible for converting folates to tetrahydrofolate, the reduced folate carriers which function in the transfer of carbon units. These carbon units are responsible for de novo purine synthesis and the methylation of purine to thymine in DNA synthesis. To avoid excessive destruction of host cells, leucovorin (a folate analogue) is used to rescue cells from MTX inhibition. ${ }^{30}$ In cancer chemotherapy, routine monitoring of drug concentrations has been practical only for 
methotrexate (MTX). The primary setting for pharmacokinetic monitoring of MTX done only if uses in high doses as adjuvant therapy for osteosarcoma, for single-agent treatment of intracranial lymphomas, and in combination therapy of childhood leukemia as well as adult and pediatric non- Hodgkin lymphomas. ${ }^{31}$

Serum concentrations and pharmacokinetic parameters of MTX are not related with outcome of ALL. Prognoses based on single-drug pharmacokinetic estimates within a complex multiple-agent protocol appear to be unreliable. However, therapeutic drug monitoring of HD-MTx remains a useful tool for early detection of impaired elimination and thus avoiding systemic toxicity. ${ }^{12}$ But it was not done in this study as this serological test is not available in our country. Here, we strictly maintained the hyper hydration, urine alkalinity, leucovorin rescue. We also routinely assessed serological and biochemical investigations for early detection and prevention of toxic effects of HDMTX.

MTX is poorly soluble at acidic $\mathrm{pH}$, and its metabolites, 7-OH-MTX and DAMPA, are six- to tenfold less soluble than MTX, respectively. An increase in the urine $\mathrm{pH}$ from 6.0 to 7.0 results in a 5 to 8 fold greater solubility of MTX and its metabolites. This finding encourages the recommendation of Intravenous hyper hydration and urine alkalinization. Hydration started from 12 hours before MTX infusion and continuing up to 24-48 hours, at the rate of $2.5-3.5$ liters of fluid $/ \mathrm{m}^{2} / 24$ hours. Urine alkalinization done with sodium bicarbonate at the dose of $40-50 \mathrm{mEq}$ per liter of I/ $\mathrm{V}$ fluid; prior to, during, and after the administration of HDMTX along with hydration. Urinary alkalinization also reduces the risk of intratubular renal crystal formation. ${ }^{32}$

For more than 30 years, leucovorin rescue has been a cornerstone of HDMTX treatment. Early HDMTX protocols were built on the observation that MTX toxicities could be prevented or ameliorated in patients with high plasma MTX concentrations who received pharmacokinetically guided doses of leucovorin. Leucovorin is particularly effective in the prevention of myelosuppression, GI toxicity, and neurotoxicity during treatment with HDMTX. Standard chemotherapy protocols now include leucovorin administration within 24 to 36 hours of HDMTX to prevent normal cells from suffering injury. ${ }^{33}$

Assessment of renal function may be a useful means of monitoring plasma MTX concentrations during HDMTX for ALL and $\mathrm{NHL}^{34}$ We had assessed estimated Creatinine Clearance (CCr) and GFR (Schwartz method) as a method of renal function in our patients by considering all above mentioned criteria as MTX level cannot be done in our country and follow up also done for six months after chemotherapy. Only two patients developed $\mathrm{CCr}<100$ during chemotherapy which subsequently became normal in next follow-up. There was no significant deterioration of renal functions which was also observed by Maryna KR et al. and Ridolfi L et al. 35,36 The vast majority of MTX is cleared by the kidneys (more than 90\%). Using hyper hydration of fluids to induce high urinary flow rates protects the kidney from injury during treatment with HDMTX. Intavenous fluids can also be used to correct hypovolemia and reduce the risk of HDMTX associated nephrotoxicity.

Proper monitoring and supportive care along with tailoring treatment is vital in improving cure rates and minimizing toxicities in childhood ALL. ${ }^{37}$ In our study, clinical monitoring, hydration, urine alkalization, GFR monitoring, and leucovorin rescue remain essential to HDMTX administration. Among these, ensuring a urine $\mathrm{pH}$ of $>7.0$ and prehydration at least 06 hours before start of HDMTX infusion, bedside $\mathrm{pH}$ monitoring per void, intravenous hydration, and exact timing of first dose of leucovorin are not to be compromised. Though monitoring methotrexate level is necessary for every cycle to detect early complication of HDMTX we could not do that due to unavailability of this test in our country rather we monitored drug toxicities by above mentioned parameters.

In different studies the common toxicities were encountered like vomiting, diarrhea, mucositis, fever, myelosuppression, and elevated transaminase levels. $11,12,20-22,38-40$ In this study, gastrointestinal toxicity in the form of vomiting $(70 \%)$ was commonly found.

Hematological toxicity in the form of v3.0 (CTCAE) grade- 3 \& 4 neutropenia was observed in $83 \%$ cycles and were higher than what the other studies have reported $25 \%{ }^{23}$ and $8-9 \% .{ }^{41,42}$

GIT toxicities in the form of vomiting, mucositis and diarrhea occurred in $70 \%, 66 \%$ and $12.5 \%$ respectively which was much higher than other studies $23,41-43$ may be as because we evaluated different type of diseases with different doses of HDMTX.

Fever was present in $31.25 \%$ cycles in our study which was similar to the incidence (30\%) reported by Rask et al. ${ }^{41}$ and $28 \%$ by Kapoor et al. ${ }^{23}$ 
Abnormal liver function observed in $8.40 \%$ of cycles were not comparable to those reported in other studies $35 \%{ }^{23}$ and $50-64 \% .{ }^{44,45}$ These abnormalities were transient and reversible as also observed by others and, in children, have not been reported to result in chronic liver disease. ${ }^{46}$

Creatinine clearance has been generally accepted as a clinically useful measure of GFR despite some limitations. The accuracy of creatinine clearance is influenced by the completeness of timed urine collections, the amount of meat in the diet and the method of cooking, the within-subject and analytical variability, strenuous exercise, and stress trauma, severe infection, and the menstrual cycle. Creatinine clearance is proportional to body size, resulting in gender differences. Correction for lean body mass or body surface area may eliminate or reduce the gender variation. ${ }^{47}$

Cytogenetics is not available in our country and also for many patients unable to afford from abroad. Only few patients were able to do this test. So this has been observed only and not included in the study.

We followed up all patients by observing $C B C$, serum electrolyte, urea, creatinine, ALT every fortnightly for at least 06 months after HDMTX and none of them developed renal or other complications in long run.

\section{Conclusion}

It has been seen that HDMTX is safe and effective with minimum toxicities. With appropriate supportive care, toxicities are reversible even in the settings of resource limited countries like Bangladesh.

\section{Recommendation}

HDMTX can be given in a tertiary care center in developing countries, without any significant life threatening complications. Even with unavailability of serum MTX level monitoring, observing routine biochemical and serological profiles were sufficient to avoid toxicities. Trained nurses and medical staffs including meticulous monitoring of treating oncologist is the mainstay of early detection and prompt management of complications if arise. This topics study has been studied for first time, so it need further studies required to established this alternate pathway.

\section{References}

1. Smith MA, Altekruse SF, Adamson PC, Reaman $\mathrm{GH}$, Seibel NL. Declining Childhood and adolescent cancer mortality. Cancer. 2014;120: 2497- 06.
2. National cancer institute's Cancer in Children and Adolescents. Available from: https:// www.cancer.gov/types/childhood-cancers/childadolescent-cancers-fact-sheet.

3. Frei E 3rd, Blum RH, Pitman SW, Kirkwood JM, Henderson IC, Skarin AT, et al. High dose methotrexate with leucovorin rescue. Rationale and spectrum of antitumor activity. Am J Med. 1980; 68: 370-76.

4. Widemann BC, Adamson PC. Understanding and managing methotrexate nephrotoxicity. Oncologist. 2006;11: 694-03.

5. Methotrexate Full Prescribing Information, http:/ leditor.apppharma.com/PIs/Methotrexate_ Inj_451043B_Jan_08.pdf

6. Tracy W, Dotson E,Tuten A, Phillips G, Maddock $K$. Evaluation of incidence and risk factors for high-dose methotrexate-induced nephrotoxicity. J Oncol Pharm Practice. 2015; 1-7.

7. Alvarnas J, Brown P, Aoun P, Peter FC, Karen K, Stevan K, et al. NCCN Clinical Practice Guidelines in Oncology: Acute Lymphoblastic Leukemia v1.2014, www.nccn.org. http:// williams.medicine.wisc.edu/all.pdf

8. Biermann JS, Adkins D, Benjamin R, Brigman B, Chow W, Conrad EU et al. Bone cancer: Clinical Practice Guidelines in Oncology. JNCCN Journal of the National Comprehensive Cancer Network. 2007;5:420-37.

9. Zelenetz A, Gordon LI, William GW, Abramson JS, Advani R, Glen MJ, et al. NCCN Clinical Practice Guidelines in Oncology: Non-Hodgkin's Lymphoma v3.2014, www.nccn.org. https:// www.nccn.org/professionals/physician_gls/ f_guidelines.asp.

10. Aimee Angle-Zahn. Methotrexate for Use in Pediatric Populations. Second Meeting of the Subcommittee of the Expert Committee on the Selection and Use of Essential Medicines; 2008; 29 Sep; Geneva.

11. Minnie A, Judith O, CH Pui, David K, Gaston KR, Diane F, et al. High-Dose Methotrexate Improves Clinical Outcome in Children With Acute Lymphoblastic Leukemia: St. Jude Total Therapy Study X. Medical and Pediatric Oncology. 1988;16:297-03 
12. Martelli N, Mathieu O, Margueritte G, Bozonnat MC, Daurès JP, Bressolle F, et al. Methotrexate Pharmacokinetics in Childhood Acute Lymphoblastic Leukaemia: A Prognostic Value. J Clin Pharm Ther. 2011;36:237-45.

13. Temming P, Jenney $M$. The Neurodevelopmental Sequelae of Childhood Leukaemia and its Treatment. Arch Dis Child. 2010;95: 936-40.

14. Moe PJ, Holen A. High-dose Methotrexate in Childhood ALL. Pediatr Hematol Oncol. 2000;17:615-22.

15. Goorin AM, Perez-Atayde A, Gebhardt M, Andersen JW, Wilkinson RH, Delorey MJ, et al. Weekly high-dose methotrexate and doxorubicin for osteosarcoma: the Dana-Farber Cancer Institute/the Children's Hospital-study III. J Clin Oncol. 1987;5:1178-84.

16. Katherine AJ, Goorin AM, Robert M. Chemotherapy in the management of osteosarcoma. www.Up-To-Date.com available from http://cursoenarm.net/UPTODATE/ contents/mobipreview.htm?38/52/ 39745?source=see_link.

17. Von Stackelberg A, Reinhard H, Buhrer C, Fengler R, Schaub GJ, Reiter A et al High-dose as compared with intermediate-dose methotrexate in children with a first relapse of acute lymphoblastic leukemia. Blood. 2008; 111:2573-80.

18. Ruggiero A, Conter V, Milani M, Biagi E, Lassareschi I, Sparano P, et al. Intrathecal chemotherapy with antineoplastic agents in children. Paediatr Drugs.2001; 3:237-46.

19. Fleischer, G. Sodium methotrexate. Physician Desk Reference: A Concise Drug Guide for Pediatrics. Montvale, NJ: Thomson Healthcare; 2007. p 214-15.

20. Peter BVKN, Kjeld S, Henrik S. Influence of Methylene Tetrahydrofolate Reductase Polymorphisms and Co-administration of antimetabolites on Toxicity after High Dose Methotrexate. European Journal of Haematology. 2008;81:391-98.

21. Clara P, Wataru WS, Wang YM, Jay H. Evaluation of Methotrexate Overall Toxicity of High-Dosage Regimens. Medical and Pediatric Oncology. 1979;6: 219-28.
22. Helene P, Maryline P, Marylene C, Genevieve M. Synvie H, Dominique HB. Reversal of Neurologic Disturbances Related to High-Dose Methotrexate by Aminophylline. Medical and Pediatric Oncology. 2001;36: 662-64.

23. Kapoor G, Sinha R, Abedin S. Experience With High Dose Methotrexate Therapy in Childhood Acute Lymphoblastic Leukemia in a Tertiary Care Cancer Centre of a Developing Country. Pediatr Blood Cancer. 2012;59:448-53.

24. Chessells JM. Recent advances in management of acute leukaemia. Archives of disease in childhood. 2000;82:438-42.

25. Philip L, Jeffrey ML, Jonathan DF Editor. Lanzkowsky's Manual of Pediatric Hematology and Oncology. $6^{\text {th }}$ edt. Oxford, UK: Elsevier,2016, p345.

26. Sun XF, Zhen ZJ, Lui DG, Xia Y, He YJ, Wang $Z H$, Lin JY, Guan ZZ. Improved treatment outcome in Chinese children and adolescents with Burkitt's lymphoma and large cell lymphoma by using the modified B-non-Hodgkin's lymphoma-Berlin-Frankfurt-Münster-90 protocol. Eur J Haematol. 2006; 77: 365-71.

27. Meyers PA. Malignant bone tumors in childhood: Osteosarcoma. Hematol Oncol Clin North Am. 1987; 1: 655-65

28. Melanie MH, Eveline SJMB, and Maroeska WML. Survival Trends and Long-Term Toxicity in Pediatric Patients with Osteosarcoma. Sarcoma. 2012;1-5.

29. Chessells JM.Maintenance Treatment and Shared Care in Lymphoblastic Leukaemia. Arch Dis Child.1995;73:368-73.

30. Lennard I. Therapeutic Drug Monitoring of Antimetabolic Cytotoxic Drugs. Br J Clinic Pharmacol.1999;47:141-43.

31. Steven PT, Bruce AC. Concepts in Use of Highdose Methotrexate Therapy. Clinical Chemistry.1996; 42:8;1322-29.

32. Brigitte CW, Peter CA. Understanding and Managing Methotrexate Nephrotoxicity. The Oncologist. 2006;11:694-03

33. Rahiem Ahmed YAA, Hasan Y. Prevention and Management of High Dose Methotrexate Toxicity. J Cancer Sci Ther. 2013;5:106-12. 
34. Xu WQ, Zhang LY, Chen XY, Pan BH, Mao JQ, Song $\mathrm{H}$, et al. Serum Creatinine and Creatinine clearance for Predicting Plasma Methotrexate Concentrations after High dose Methotrexate Chemotherapy for the Treatment for Childhood Lymphoblastic Malignancies. Cancer Chemother Pharmacol. 2014;73:79-86.

35. Maryna KR, Marta K, Jolanta W. Renal Function During Treatment for Acute Lymphoblastic Leukemia in Children. Pediatric Nephrology. 2005;20:782-5.

36. Ridolfi L, Barisone E, Vivalda M, Vivenza C, Brach DPA, Leone L, et al. Toxicity of High dose Methotrexate Repeated Infusions in Children Treated for Acute Lymphoblastic Leukemia and Osteosarcoma. Minerva Pediatrica. 1996;48: 193-200

37. Martelli N, Mathieu O, Margueritte G, Bozonnat MC, Daurès JP, Bressolle F, et al. Methotrexate Pharmacokinetics in Childhood Acute Lymphoblastic Leukaemia: A Prognostic Value?. J Clin Pharm Ther. 2011;36:237-45.

38. Olafur GJ, Barton AK. Methotrexate and Childhood Leukemia. Cancer Investigation. 1991; 9: 53-60.

39. Holmboe L, Andersen AM, Mørkrid L, Slørdal L, Hall KS. High dose Methotrexate Chemotherapy: Pharmacokinetics, Folate and Toxicity in Osteosarcoma Patient. Br J Clin Pharmacol. 2012;73:106-14.

40. M. Takami, Y Kuniyoshi, T Oomukai, T Ishida, Y Yamano. Short communication- Severe Complications after High Dose Methotrexate Treatment. Acta Oncologica.1995;34,611-12.
41. Rask C, Albertioni F, Bentzen SM, Schroeder $\mathrm{H}$, Peterson C. Clinical and Pharmacokinetic Risk factors for High-dose Methotrexate-induced Toxicity in Children with Acute Lymphoblastic Leukemia: A Logistic Regression Analysis. Acta Oncologica. 1998;37:277-84.

42. Kinoshita A, Kurosawa Y, Kondoh K, Suzuki T, Manabe A, Inukai T, et al. Effects of Sodium in Hydration solution on Plasma Methotrexate Concentrations following High-dose Methotrexate in Children with Acute Lymphoblastic Leukemia. Cancer Chemother Pharmacol. 2003;51:256-60.

43. Rask C, Albertioni F, Schrøder H, Peterson C. Oral Mucositis in Children with Acute Lymphoblastic Leukemia after High-dose Methotrexate Treatment without Delayed Elimination of Methotrexate: Relation to Pharmacokinetic Parameters of Methotrexate. Pediatr Hematol Oncol. 1996;13:359-67.

44. Raje NS, Vaidya SJ, Kapoor G, Pai SK, Nair CN, Kurkure PA, et al. Low Incidence of CNS Relapse with Cranial Radiotherapy and Intrathecal Methotrexate in Acute Lymphoblastic Leukemia. Indian Pediatr. 1996;33:556-60.

45. Arya LS. Acute Lymphoblastic Leukemia: Current Treatment Concepts. Indian Pediatr. 2000;37:397-06.

46. Weber BL, Tanyer G, Poplack DG, Reaman GH, Feusner JH, Miser JS, et al. Transient Acute Hepatotoxicity of High-dose Methotrexate therapy During Childhood. NCl Monogr. 1987;207-12.

47. Sokoll LJ, Russell RM, Sadowski JA, Morrow FD. Establishment of creatinine clearance reference values for older women. Clin Chem. 1994;40:2276-81. 